\title{
THE DEVELOPMENT OF PVDF/PEI BLENDED MEMBRANE: EFFECT OF STIRRING TIME ON MEMBRANE CHARACTERISTICS AND PERFORMANCE
}

\author{
Nita Kusumawati ${ }^{1, *}$, Pirim Setiarso ${ }^{2}$, Agus Budi Santoso ${ }^{3}$, Setya Chendra \\ Wibawa $^{4}$ and Supari Muslim ${ }^{5}$ \\ ${ }^{1,2}$ Department of Chemistry,Universitas Negeri Surabaya, Ketintang, Surabaya, Indonesia \\ ${ }^{3,5}$ Department of Electrical Engineering, Universitas Negeri Surabaya, \\ Ketintang, Surabaya, Indonesia \\ ${ }^{4}$ Department of Informatics Engineering, Universitas Negeri Surabaya, \\ Ketintang, Surabaya,Indonesia \\ *E-mail: nkusumawati82@yahoo.com
}

\begin{abstract}
The increased characteristics and performance of polyvinylidene fluoride (PVDF) membrane were investigated using polyetherimide (PEI) as a high-performance co-polymer for increased porosity, mechanical strength, PWF and thermal also chemical stability. The blend solution was prepared using a composition 2\%PVDF/12\%PEI/84\%NMP/2\%PEG-6000 (wt.\%) with varying stirring time (7h, 12h, 16h, and 20h). The formation of a solid PVDF/PEI membrane was obtained using a non-solvent induced phase inversion (NIPS) method. Analysis of physical (surface and cross-section morphology, porosity, pore size) and mechanical (Young's modulus) characteristics, performance (PWF), thermal and chemical stability of the blended membranes were performed to evaluate the significance of stirring time effect. The resulting infrared spectra have confirmed the formation of PVDF/PEI blended membrane. All PVDF/PEI blended membranes were found to have symmetric structures with porosity $6.17 \%-30.64 \%$ and pore size $0.204 \mathrm{~nm}-0.366 \mathrm{~nm}$. The increase in mechanical strength can be seen from changes in Young's modulus values as the stirring time increases up to 12 hours. However, the stirring time for 16 and 20 hours resulted in a cast solution with too high viscosity resulting in a defect in the casting film using the automatic-casting knife. Increasing the homogeneity of PVDF/PEI cast solution as increasing stirring time has led to PEI characteristic properties that are capable of producing high PWF. This PVDF/PEI mixing method is a potential solution to obtain higher PVDF thermal stability and PEI chemical resistance.
\end{abstract}

Keywords: Membrane, Composite, Blend, Polyvinylidene Fluoride, Polyetherimide

(C) RASĀYAN. All rights reserved

\section{INTRODUCTION}

Polyvinylidene fluoride (PVDF) is a semi-crystalline polymer with high mechanical strength as well as $\mathrm{UV}$, thermal and chemical resistance, which is easy to prepare. These advantages have made PVDF usable in a large number of separation applications, including micro and ultrafiltration ${ }^{1-5}$. The intended applications include drug transportation system, water softening, biological separation, sensory and protective coatings ${ }^{6-8}$. However, several weaknesses of the PVDF membrane have been detected, especially in the high fouling potential and classical reverse phenomena that apply to the mechanical characteristics and pure water permeability (PWF) produced ${ }^{9}$. The mechanical strength of the PVDF membrane will increase as PWF decreases in the membrane. The high hydrophobicity of PVDF has made membranes have a high fouling potential due to organic pollutants deposition in the surface and internal pore, resulting in decreased PWF and specific permeability ${ }^{10-13}$.

A number of attempts to make the whole hydrophobic membrane become hydrophilic, such as surface coating, chemical grafting, and blending or addition of inorganic hydrophilic additives are performed to achieve improved hydrophilic and PWF properties as well as reduction of the membrane fouling

Rasayan J. Chem., 12(2), 975-986(2019)

http://dx.doi.org/10.31788/RJC.2019.1225104

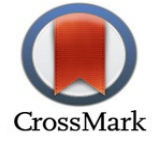


potential $^{14-27}$. Among these efforts, blending of polymers with higher hydrophilic properties such as polyetherimide (PEI) into PVDF cast solution to form composite membranes has shown effectiveness in reducing hydrophobicity and fouling potential of membranes also predicted to be able to present increased mechanical strength and PWF at the same time due to the unique morphology possessed by the PEI membrane ${ }^{28-29}$.

The PEI membrane can be used in a variety of different applications, including microfiltration, ultrafiltration and gas separation ${ }^{29-32}$. The application can be achieved through its preparation as a single material or hybrid, either by using additives or without additives, to obtain new composite membranes ${ }^{33}$. With some alternative inductors on simple phase separation methods applied to obtain the asymmetric structure, PEI is believed to have excellent mechanical strength and performance, also high thermal stability $\left(\leq 500{ }^{\circ} \mathrm{C}\right)^{34}$. However, the weakness of PEI, especially concerning lower chemical stability compared with many other commercial polymers, including PVDF, should continue to be pursued. The success of this effort will further expand the application of PEI membranes especially if the process is directly related to extreme media, such as at very low (acid) or high $\mathrm{pH}$ (alkaline) and oxidative. By blending the polymers of PEI and PVDF, membranes that can be obtained not only have high porosity and mechanical strength as well as excellent performance and thermal stability typical of PEI membrane, but also high chemical stability typical of PVDF membrane.

This study studies the membrane performance improvement which is sought through the addition of PEI with special compositions to obtain higher porosity and lower pore size, which is expected to produce an increase in the mechanical strength. While an increase in membrane hydrophilicity triggered by the nature of PEI is expected to increase PWF. In addition, the presence of PEI in the composite membrane matrix is expected to be able to trigger an increase in thermal resistance and vice versa, the presence of PVDF is expected to produce increased chemical stability, especially in acidic environments.

\section{EXPERIMENTAL}

\section{Material and Methods}

Polyvinylidene fluoride (PVDF) (molecular weight 35,000), polyetherimide (PEI) (molecular weight $354,000)$ and N-methyl-2-pyrrolidone (NMP) ( $\geq 99.7 \%)$ were purchased from Sigma-Aldrich Ltd. (Singapore). Polyethylene glycol (molecular weight 6000) was purchased from PT. Brataco Chemical (Indonesia). Non-woven gauze (254 mesh) obtained from PT. KasaHusadaWiraJatim (Indonesia). Sulfuric acid $\left(\mathrm{H}_{2} \mathrm{SO}_{4}\right)(>98 \%)$ and sodium hydroxide $(\mathrm{NaOH})(\geq 98 \%)$, were purchased from Ajax Finichem (Australia) and Sigma-Aldrich Ltd (Singapore) respectively.

\section{Preparation of PVDF/PEI Blended Membrane}

Preparation of PVDF/PEI blended membrane in this research was conducted using non-solvent induced phase separation (NIPS) method. Dissolution of a number of polymers, consisting of 2 (wt.\%) PVDF, 12 (wt.\%) PEI, and 2 (wt.\%) PEG-6000 in 84 (wt.\%) NMP was carried out to prepare PVDF/PEI blended membrane casting solutions. To ensure the solubility of the three polymeric materials in NMP, stirring has been performed using a magnetic stirrer with varying time $(7 \mathrm{~h}, 12 \mathrm{~h}, 16 \mathrm{~h}$, and $20 \mathrm{~h})$ at $60^{\circ} \mathrm{C}$. To prevent the formation of air bubbles in a liquid film, it is degassed for $18 \mathrm{~h}$ at room temperature. The polymer solution was cast with a thickness of $700 \mu \mathrm{m}$ on a non-woven gauze-coated glass substrate using an automatic casting knife. To ensure the formation of a defect-free polymer solution, post-casting degassed was carried out for 30 minutes, before being immersed in water non-solvent for 2 hours at 40 ${ }^{\circ} \mathrm{C}$. The phenomenon of liquid-liquid demixing between the solvent in the cast solution and the nonsolvent from the coagulation bath will result in phase separation and induce the formation of a solid membrane. To ensure the absence of solvents and porogens left behind, the membrane is immersed all day in distilled water at room temperature. The membrane drying process was carried out in the open air for 24 hours. The PVDF/PEI blended membrane cast solution composition is presented In Table-1.

\section{Membrane Characterizations Chemical Characterization}

The membrane chemical structure characterized by Fourier transform infrared spectroscopy (FTIR) (Nicolet IS10 Thermo Scientific) includes a wavenumbers range of 4,000-400 $\mathrm{cm}^{-1}$. Given this 
characterization, the successful blending of PVDF and PEI can be ensured and changes in the molecular structure of membrane constituents after thermal and chemical stability tests in acid and base environments can be confirmed.

Table-1: The PVDF/PEI Blended Membrane Composition

\begin{tabular}{c|c|c|c}
\hline No. & Material Membrane & Membrane Type & Stirring Time (h) \\
\hline 1. & PVDF & M1 & 7 \\
\hline 2. & PVDF/PEI & M2 & 7 \\
\hline 3. & PVDF/PEI & M3 & 12 \\
\hline 4. & PVDF/PEI & M4 & 16 \\
\hline 5. & PVDF/PEI & M5 & 20 \\
\hline 6. & PEI & M6 & 7 \\
\hline
\end{tabular}

\section{Physical Characterization}

To investigate the effect of stirring time on membrane morphology, both on surface and cross-section, an analysis using scanning electron microscopy (SEM) (Zeiss EVO MA10, Germany) was performed. Particularly for the characterization of cross-sections, the membrane samples are prepared by slicing using a microtome (MikrotomyMicrom, HM315). To get a near-real image, before SEM analysis, the membrane sample was coated using gold by a sputtering method for 50 seconds. SEM analysis is done with $20.0 \mathrm{kV}$ voltage acceleration.

In terms of physical morphology, the number of pores or porosity and pore size are important parameters that can provide a general overview of membrane mechanical strength and permeability. To determine porosity by the gravimetric method, the immersion of membrane samples in distilled water was carried out for $24 \mathrm{~h}$. Before weighing, all superficial water on the membrane surface was removed using filter paper. The membrane was immediately weighed to get wet weight data, while to obtain dry weight, membrane drying with an air circulation oven $\left(60^{\circ} \mathrm{C}\right)$ was carried out for 24 hours. The drying was continued using a vacuum oven at $80{ }^{\circ} \mathrm{C}$ with the same time interval and ending with dry membrane weighing. Membrane porosity can be calculated using equation (1).

$$
P(\%)=\frac{W_{w}-W_{d}}{p_{w} \times A x \delta} \times 100
$$

Where, ${ }^{P}$ is porosity (\%), ${ }_{w}$ is wet weight and ${ }^{W_{d}}$ is dry weight. Both membrane weights are measured in grams. Meanwhile, $P_{w}$ is the pure water density expressed in $\mathrm{g} / \mathrm{cm}^{3}$ and $^{A}$ is the wet membrane thickness, expressed in $\mathrm{cm}$. To reduce experiment error, the reported porosity value is the average of the three sample measurements.

In this study, pore size $\left(r_{m}\right)$ is determined by the Guerout-Elford-Ferry equation based on permeability (flux) and porosity of the membrane.

$$
r_{m}=\sqrt{\frac{(2.9-1,75 \varepsilon) \times 8 \eta l Q}{\varepsilon \times A x \Delta P}}
$$

Where $\eta_{\text {is }}$ water viscosity $\left(8.9 \times 10^{-4} \mathrm{~Pa} . \mathrm{s}\right) ; Q_{\text {is }}$ permeating volume that is able to pass through the membrane each time unit expressed in $\mathrm{m}^{3} / \mathrm{s}$, while $\Delta P_{\text {is }}$ the operating pressure of the membrane reactor which in this case is $0.1 \mathrm{MPa}$.

\section{Mechanical Characterization}

Membrane mechanical characteristics were analyzed using universal tensile tester (RCT/10KN/AF TOYO SEIKI, Japan). Both ends of the $150 \mathrm{~mm} \times 100 \mathrm{~mm}$ membrane, previously dried at $30{ }^{\circ} \mathrm{C}$ for 24 hours, were attributed to a machine of an initial length of $30 \mathrm{~mm}$. The measurement of membrane stress and 
strain was carried out with a constant strain speed of $20 \mathrm{~mm} / \mathrm{min}$ at room temperature. The reported result was obtained from the mean measurements of three samples to ensure reproducibility.

\section{Pure Water Permeability (PWF)}

Membrane permeation performance is measured under specific operational conditions (room temperature, 1 bar) using a dead-end reactor membrane (self-made). Measurements were made to membranes with surface area $0.00246176 \mathrm{~m}^{2}$. Before pores measurement, each membrane must be compacted with pure water at a pressure of 1.5 bar for 30 minutes, to get a stable flux. The reported result was the average of the three membrane measurements. The pure water permeability expressed in $\mathrm{Lm}^{-2} \mathrm{~h}^{-1} \mathrm{bar}^{-1}$ is calculated using equation (3).

$$
P W F-\frac{V}{A x t}
$$

Where $\mathrm{V}$ is the volume of permeate expressed in $\mathrm{L}, \mathrm{A}$ is membrane area expressed in $\mathrm{m}^{2}$ and $\mathrm{t}$ is the time required until all permeates succeed through the membrane, expressed in $\mathrm{h}$.

\section{Thermal Stability}

Membrane samples weighing $0.2 \mathrm{~g}$ were analyzed for its thermal stability using Thermal Gravimetric Analysis (TGA, Perkin Elmer STA-6000). Thermal resistance testing of membrane samples was performed at $20-700{ }^{\circ} \mathrm{C}$ with an increasing rate of $20{ }^{\circ} \mathrm{C} / \mathrm{min}$.

\section{Chemical Stability}

Chemical resistance of the membrane was studied each through immersion steps in 80 vol.\% sulfuric acid and $80 \mathrm{wt} . \%$ sodium hydroxide. Changes in functional groups before and after testing were evaluated by FTIR. Using the results of this analysis, the disappearance and appearance of specific functional groups in the membranes produced after treatment in acid and base environments can be confirmed.

\section{Preparation of PVDF/PEI Blended Membrane}

\section{RESULTS AND DISCUSSION}

Blending the PEI into the PVDF polymer matrix not only has resulted in less membrane shrinkage but has also affected PWF as well as mechanical, thermal and chemical resistance of the membrane. This change has increased significantly along with the increasing of the cast solution stirring time. However, the application of too long stirring time (16 hours and 20 hours) has resulted in a cast solution with a level of viscosity that is too high to be able to be cast using an automatic casting knife. Therefore, in this report, the discussion is limited to four types of membranes, namely M1; M2; M3; and M6.

In previous research, the PVDF membrane prepared in the non-woven support layer has shown the formation of asymmetric pore structures with ultrafiltration pore size, but with the significant membrane, shrinkage induced by macrovoid. The membrane also exhibits low chemical resistance when intersected with strong base environments such as sodium hydroxide ${ }^{35}$. This condition makes its use limited. On the other hand, the results of PEI membrane preparation in previous experiments have shown the formation of symmetric pore structures with high pore density and minimal macrovoids, mechanical strength, PWF, and higher thermal resistance compared to PVDF. The PEI membrane is also found to be more resistant to the alkaline environment. However, the PEI membrane is known to have less chemical resistance to the acid medium. The advantages of PEI polymer have become the background of this material selection as a blending agent for PVDF polymers. Figure-1 shows the physical appearance of a PVDF/PEI blended membrane prepared with different PEI levels.

\section{Membrane Characterization Chemical Characterization}

FTIR has an important role in confirming the successful blending of PVDF and PEI, as shown in the spectra in Fig.-2. From the pure PVDF (M1) IR spectrum, identified the characteristic peak of the CF- 
functional group at wavenumber 1000-1400 $\mathrm{cm}^{-1}$. Meanwhile, in the pure PEI IR spectrum (M6) there has been detected occurrence of the absorption peak which indicates a typical PEI functional group, which includes the wavenumber $1710-1720 \mathrm{~cm}^{-1}$ for the $\mathrm{C}=\mathrm{O}$ functional group; $1400-1600 \mathrm{~cm}^{-1}$ for $\mathrm{C}=\mathrm{C}$ aromatic; $1000-1250 \mathrm{~cm}^{-1}$ for C-N; $970-1250 \mathrm{~cm}^{-1}\left(1000-1300 \mathrm{~cm}^{-1}\right)$ for $\mathrm{C}-\mathrm{O}$ (C-O ether).

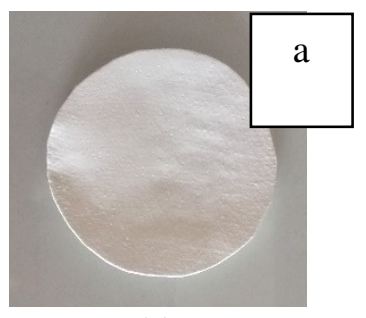

(a)

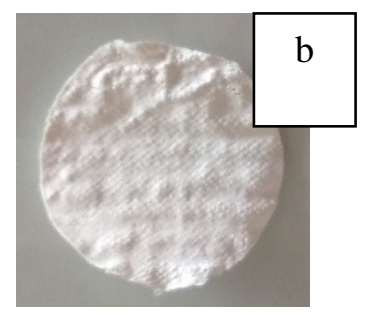

(b)

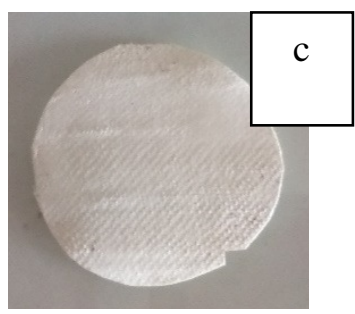

(c)

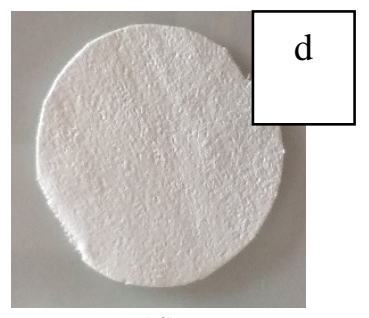

(d)

Fig.-1: Physical Appearance of the: M1 (a); M2 (b); M3 (c); and M6 (d) Membranes

The FTIR analysis results have also confirmed the success of blending of PVDF and PEI in this study (M2 and M3) through a combination of peak appearance of C-F characteristics on wavenumbers 1013.70; $1074.09 ; 1100.66 ; 1172.49 ; 1234.48 ; 1270.32 \mathrm{~cm}^{-1}(\mathrm{M} 2)$ as well as on $1013.90 ; 1074.46 ; 1101.45$; $1172.56 ; 1235.00 ; 1271.36 ; 1354.10 \mathrm{~cm}^{-1}(\mathrm{M} 3) ; \mathrm{C}=\mathrm{O}$ at the wavenumber $1716.63 \mathrm{~cm}^{-1}(\mathrm{M} 2)$ and 1717.12 $\mathrm{cm}^{-1}$ (M3); $\mathrm{C}=\mathrm{C}$ aromatic on wavenumber $1444.62 ; 1476.33 ; 1495.0 ; 1598.05 \mathrm{~cm}^{-1}(\mathrm{M} 2)$ and on 1444.65 ; $1476.65 ; 1495.22 ; 1598.34 \mathrm{~cm}^{-1}(\mathrm{M} 3)$; C-N which overlaps with $\mathrm{C}-\mathrm{O}$ ether at wavenumber 1013.70; $1074.09 ; 1100.66 ; 1172.49 ; 1234.48 \mathrm{~cm}^{-1}$ (M2) and at 1013.90; $1074.46 ; 1101.45 ; 1172.56 ; 1235.00 \mathrm{~cm}^{-1}$ (M3). In addition, there has been a noticeable increase in PEI characteristic peak intensity along with the increasing of the casting solution stirring time, although not significantly.

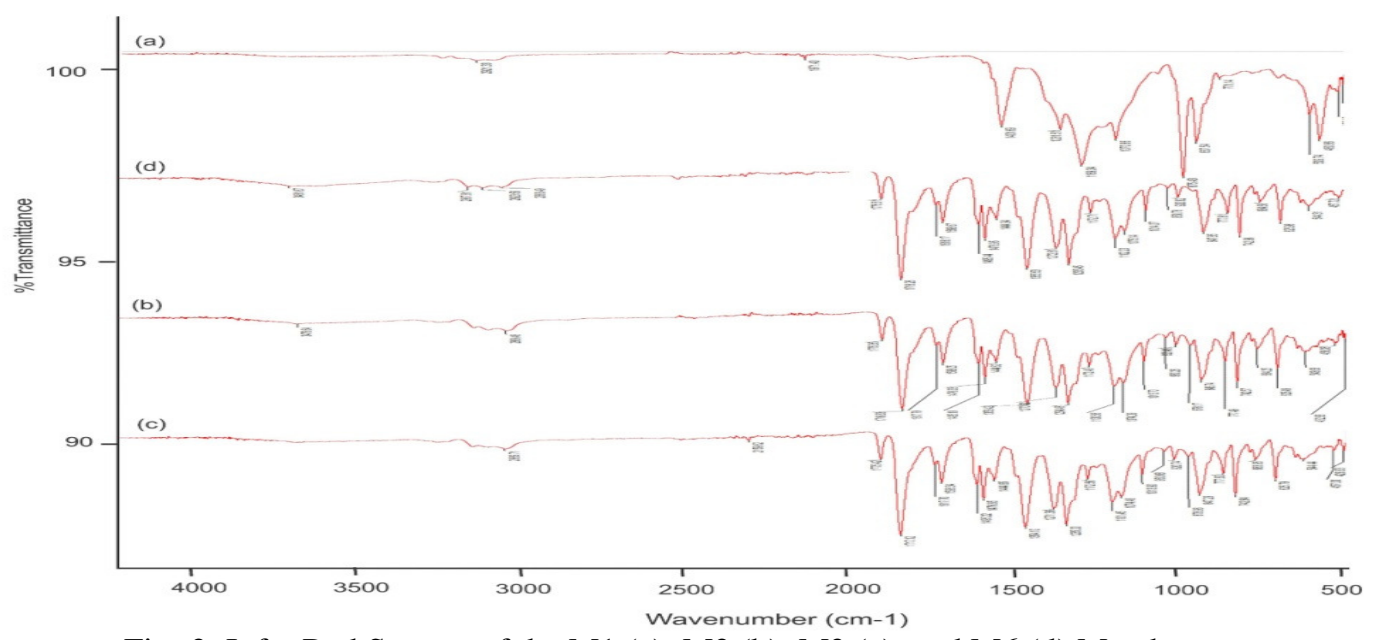

Fig.-2: Infra Red Spectra of the M1 (a); M2 (b); M3 (c); and M6 (d) Membranes

\section{Physical Characterization}

The morphological structure formation of the porous membrane is generally closely related to thermodynamics and the kinetics equilibrium formed by the solvent, additives and polymers system ${ }^{36}$. Both PVDF/PEI composite membranes were prepared using the same method and composition, but with different stirring times. Solid membranes were formed according to the phase separation behavior produced by the exchange of solvent in the cast solution with the non-solvents in the coagulation bath. The surface and cross-sections morphology of M1, M2, M3 and M6 with magnification 15,000x are presented in Fig.-3 and 4.

In Fig.-3 it appears that entire prepared PVDF/PEI membranes have a symmetric structure that combines the presence of a dense skin layer with a low thickness on the surface and a porous layer which includes micropore (sponge pore) and macrovoid at the bottom. Compared to M1 membrane, the skin layer on M2 and M3 membranes have a smaller pore size accompanied by sponge pore and macrovoid which decrease in volume as the time of stirring of the cast solution increases. 


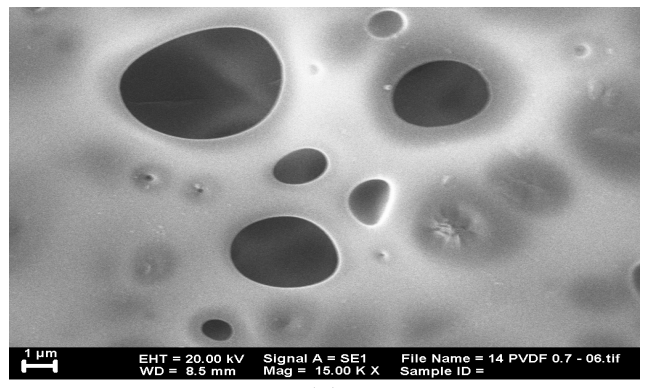

(a)

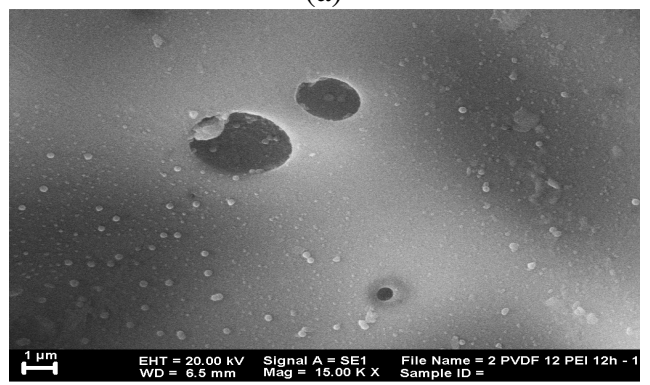

(c)

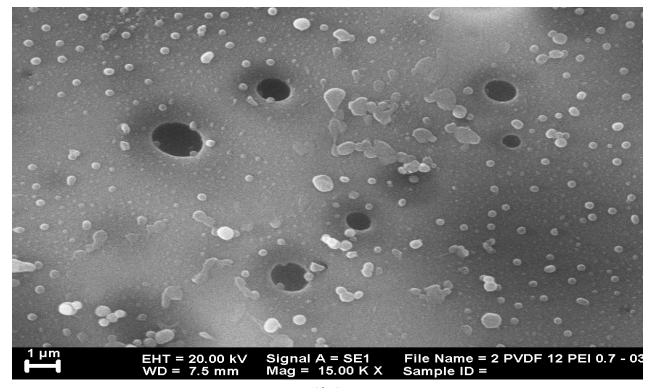

(b)

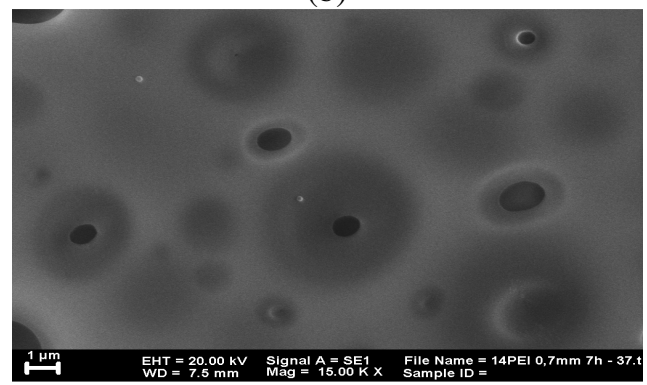

(d)

Fig.-3: Surface SEM Image of: M1 (a); M2 (b); M3 (c); and M6 (d) Membranes

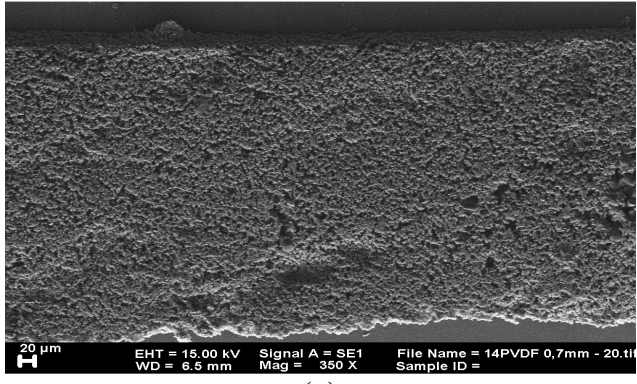

(a)

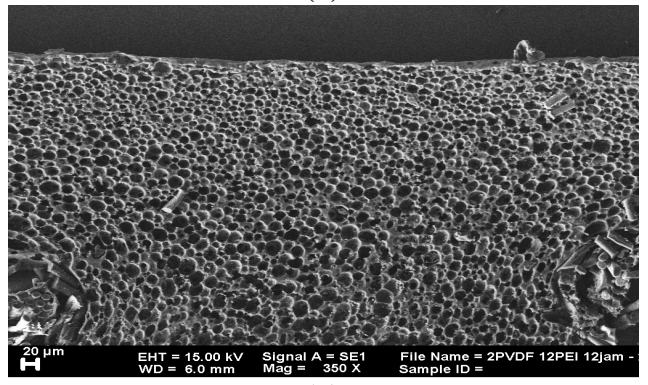

(c)

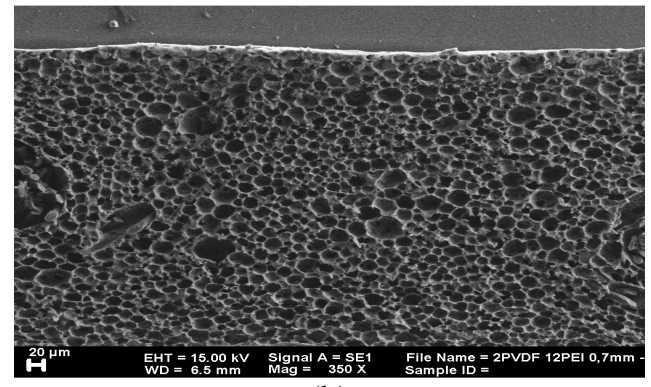

(b)

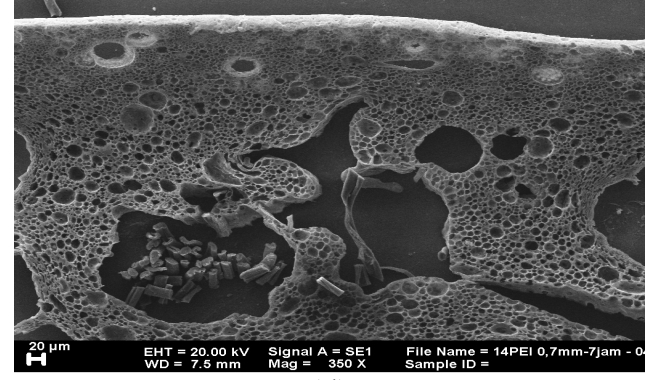

(d)

Fig.-4: Cross-section SEM Image of: M1 (a); M2 (b); M3 (c); and M6 (d) Membranes

The preparation of the PVDF/PEI cast solution with increased stirring time has resulted in membranes with pore structure and size increasingly close to pure PEI membrane (M6). Increased stirring time has induced homogeneity and optimumlyprevented the aggregation of one or more membrane particles. Changes in operational conditions in this membrane preparation have reduced disturbances to the thermodynamic equilibrium of the system and the diffusion kinetics between solvent and non-solvent that induce delayed liquid-liquid demixing. This has caused a decrease in porosity, pore size and macrovoid in PVDF/PEI membranes.

Imaging with SEM was further strengthened by porosity and pore size analysis which showed higher porosity and pore size of M1 compared to M2 and M3, as well as M6 membranes. The porosity analysis using the gravimetric method shows a porosity of $30.64 \%$ in the M1; $10.98 \%$ on the M2; $6.17 \%$ on the 
M3; and 22.17\% on the M6 membrane. In line with porosity, the results of membrane pore size analysis showed significant differences in the PVDF/PEI composite membrane resulting from different stirring times. Detected pore size appears to be $0.648 \mathrm{~nm}$ on the M2 and $0.464 \mathrm{~nm}$ on the M3 membrane. Compared with the M1 membrane having a pore size of $1.298 \mathrm{~nm}$ and an M6 membrane having a pore size of $0.745 \mathrm{~nm}, \mathrm{PVDF} / \mathrm{PEI}$ blended membrane has a pore size between the two.

\section{Mechanical Characterization}

Young's modulus is the main parameter that describes the mechanical strength of the membrane in maintaining pore size when applied external loads. In Fig.-5 was presented mechanical strength data showing an increase in PVDF/PEI membrane ability in maintaining pore size (up to $2.38 \%$ ) when the external load is applied, which is from $16248.35 \mathrm{~N} / \mathrm{m}^{2}$ resulting from stirring time for 7 hours to 16634.43 $\mathrm{N} / \mathrm{m}^{2}$ resulting from stirring time for 12 hours. This condition is closely related to the decrease in the pore and macrovoid size in the membrane as a result of a decrease in the diffusion rate of solvent and nonsolvent particles. This decrease in diffusion rate has given longer time for membrane polymer particles to interact with each other more complexly, triggering an increase in the extent of the polymer-rich structures (membrane matrix) and the decrease in the poor polymer structure (membrane pores). However, the mechanical strength of blended membranes produced from stirring for 12 hours (M3) was still lower (32.03\%) compared to pure PEI (M6) membranes. In general, the combination of high porosity and low pore size on the PEI membrane structure has produced extraordinary mechanical strength. Analysis of pore size distribution is an inevitable choice when different phenomena occur, where a combination of high porosity and slightly larger pore size on the M6 membrane is able to provide higher mechanical strength compared to M2 and M3. The only acceptable approach is that pure PEI membranes have a wide pore size distribution so that in the pore analysis the M6 membrane can be detected to have a relatively larger pore size. The combination of high porosity and extensive pore size distribution in membrane structure has made the M6 membrane capable of producing comparable mechanical strength and PWF at the same time. The mechanical strength of the PVDF/PEI blended membrane is also significantly different compared to the PVDF membrane $\left(8750.00 \mathrm{~N} / \mathrm{m}^{2}\right)$. The formation of an imperfect matrix under the applied preparation conditions is the main cause of the low PVDF (M1) membrane mechanical strength. This is characterized by a cross-section morphological of the membrane that does not form a pore completely and precisely the appearance of extensively cracks on the M1 membrane is detected.

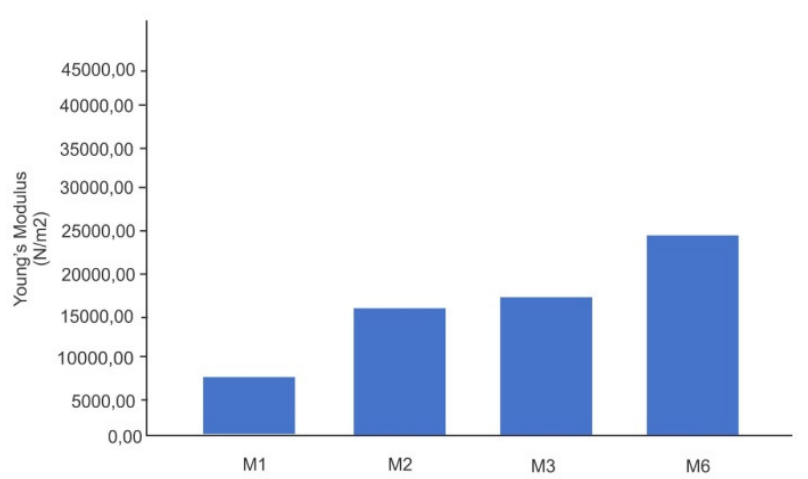

Fig.-5: The Mechanical Strength of the Prepared Membranes

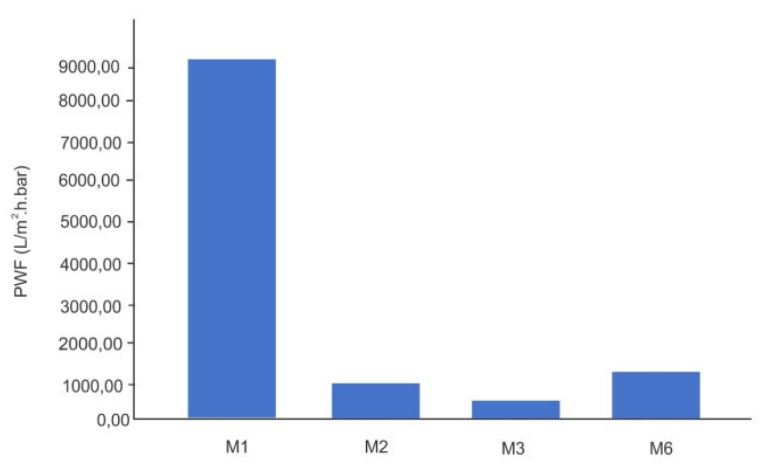

Fig.-6: Pure Water Flux of the Prepared Membranes

\section{Pure Water Flux (PWF)}

Membrane morphology is strongly influenced by two main parameters, namely the thermodynamic stability of the cast solution and the mutual diffusion rate of solvents in the cast solution and non-solvent from the coagulation bath. Only a small amount of non-solvent was needed to trigger interference with both parameters and produce phase separation in an unstable cast solution. Thermodynamic stability in the early stages of phase separation determines the formation of the skin layer. Water non-solvent generally can cause significant interference to the thermodynamic stability of PVDF and PEI cast 
solution. The big differences of solubility parameters between the solvents, which in this case is NMP, with water non-solvent has triggered an increase in the heat enthalpy $(\Delta \mathrm{H})$ and caused an unspontaneous reaction $(\Delta \mathrm{G}>0)$ in the cast solution system. This induces the acceleration of solvent and non-solvent diffusion rates and as a consequence, the most porous structure of the skin layer and highest PWF was produced. The addition of PVDF has reduced the stability of PEI solutions, due to the higher hydrophobic nature of PVDF, which increases the effective pore size and porosity of the membrane surface. The increase in stirring time was detected to reduce PWF up to $38.91 \%$. The tendency of PWF changes along with the increase in stirring time of the cast solution and the magnitude of the PWF produced compared to the PVDF and PEI membranes are shown in Fig. -6.

The solvent and non-solvents diffusion rate was closely related to the viscosity of the polymer solution and tends to increase as the stirring time of the cast solution increases ${ }^{37}$. Specifically, in the polymer blend, entanglement between membrane polymer chains has increased the viscosity of the solution. The polymer solution with high viscosity tends to inhibit the diffusion of non-solvents into polymer solutions, which were needed to induce phase separation ${ }^{38-39}$. The higher the viscosity of the cast solution will create greater inhibition for the occurrence of further non-solvent diffusion. Thus, the cast solution viscosity becomes an important parameter that determines the porous layer (sublayer) structure, as reported by Gh. Bakeri at $\mathrm{al}^{40}$. This is the cause of a decrease in PWF of the PVDF/PEI blended membrane resulting from the longer stirring time (12 h, M3 membrane). Compared with the M1 and M6 membranes, each prepared with a shorter stirring time (7 hours), the composite (M3) membrane has a lower PWF value. On Fig. -6, it appears that the M1; M2; M3; and M6 membrane, each having a PWF of $8165.93 \mathrm{Lm}^{-2} \mathrm{~h}^{-1} \mathrm{bar}^{-1}$; 958.29 $\mathrm{Lm}^{-2} \mathrm{~h}^{-1}$ bar $^{-1} ; 585.43 \mathrm{Lm}^{-2} \mathrm{~h}^{-1}$ bar $^{-1}$; and $1284.16 \mathrm{Lm}^{-2} \mathrm{~h}^{-1}$ bar $^{-1}$.

\section{Thermal Stability}

To evaluate thermal resistance, a PVDF/PEI analysis was performed using TGA. Fig.-7 shows the results of TGA analysis showing the decomposition stages of PVDF and PEI. In this case, the decrease in mass over a test temperature range shows decomposition. At a temperature of $120-340{ }^{\circ} \mathrm{C}$ the first phase of mass decrease has been detected. The mass decrease at this stage is thought to be triggered by water evaporation from the membrane matrix. The mass decrease in the second phase that occurs at $320-400{ }^{\circ} \mathrm{C}$, is predicted to be closely related to the evaporation of NMP solvents from the surface and inside the membrane matrix. The third mass decrease that lasted at $340-560{ }^{\circ} \mathrm{C}$, predicted in relation to PVDF decomposition events. These findings are in line with those reported by Liu et al which states $375{ }^{\circ} \mathrm{C}$ as the PVDF decomposition temperature, while the fourth mass decrease in the temperature range 440-650 ${ }^{\circ} \mathrm{C}$, is thought to be the decomposition stage of $\mathrm{PEI}^{10}$. This result is in line with the publication of Setyaningsih et al which states $500{ }^{\circ} \mathrm{C}$ as the PEI decomposition temperature ${ }^{41}$. Increased stirring time of the cast solution will increase the homogeneity of membrane polymer particles in the cast solution. This condition will trigger an increase in membrane pore density, which is the main cause of increased energy binding and thermal stability of the membrane. This condition will induce delay on membrane decomposition. As in the thermogram shown in Fig.-7 (b), had been detected significant changes in thermal stability of PVDF/PEI blended membrane were produced with different stirring times (7 and 12 hours). These differences include the increase in water evaporation temperature from $120-320{ }^{\circ} \mathrm{C}$ to 120 $340{ }^{\circ} \mathrm{C}$ and the release of NMP from a temperature of $320-400{ }^{\circ} \mathrm{C}$ to a temperature of $340-440{ }^{\circ} \mathrm{C}$. Increased evaporation temperatures of $\mathrm{H}_{2} \mathrm{O}$ and NMP molecules, mainly from membrane internal pores, occur because of increased membrane pore density has given rise to more significant barriers for $\mathrm{H}_{2} \mathrm{O}$ and NMP molecules to be able to escape through membrane pores. The decrease in the third and fourth stages of the M3 membrane successively increases from the temperature of $400-500{ }^{\circ} \mathrm{C}$ to $440-560{ }^{\circ} \mathrm{C}$, and from 500-640 ${ }^{\circ} \mathrm{C}$ to $560-650{ }^{\circ} \mathrm{C}$. Compared with TGA analysis results against pure PVDF (M1) and PEI (M6) membrane, M2 and M3 membrane showed higher thermal stability compared with M1 membrane and the thermal stability that appeared did not differ significantly compared to M6 membranes prepared by the same stirring time.

\section{Chemical Stability}

FTIR analysis of PVDF/PEI blended membranes (See Fig.-8) shows lower chemical stability of PEI than PVDF membranes in acidic environments. This is evident from the PEI characteristics peak appearance 
RASĀYAN J. Chem.

Vol. 12 | No. 2 |975 - 986| April - June | 2019

with lower intensity and even disappearance on IR spectrum of the PVDF/PEI blended membrane which has been immersion for 24 hours in 80 vol.\% sulfuric acid.

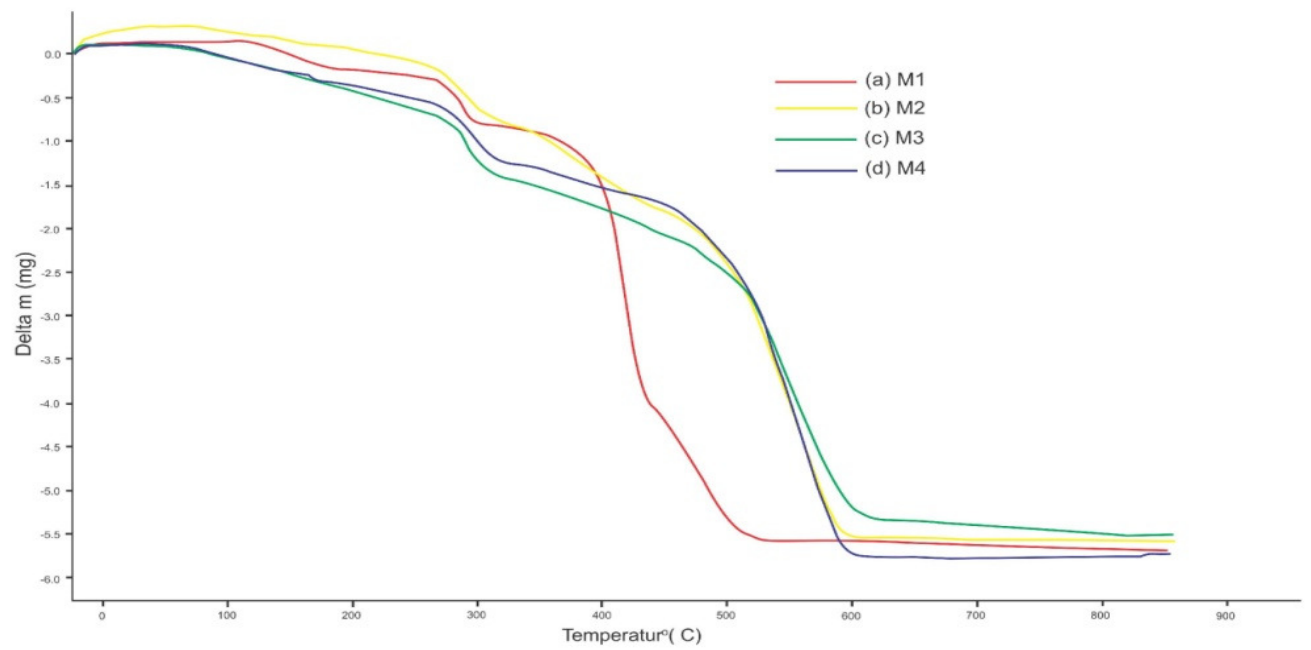

Fig.-7: TGA Trace of: M1 (a); M2 (b); M3 (c); and M6 (d) Membranes

The characteristics peak with decreased intensity include the peak of $\mathrm{C}=\mathrm{C}$ in the form of an aromatic ring, either conjugated or not at $1476.33 \mathrm{~cm}^{-1}$ and $1598.05 \mathrm{~cm}^{-1}$ for $\mathrm{M} 2$; C-O which overlaps with C-N at $1013.70 \mathrm{~cm}^{-1}, 1172.49 \mathrm{~cm}^{-1}, 1234.48 \mathrm{~cm}^{-1}$ for M2 and $1013.90 \mathrm{~cm}^{-1}, 1172.56 \mathrm{~cm}^{-1}, 1235.00 \mathrm{~cm}^{-1}$ for M3; $\mathrm{C}=\mathrm{O}$ ketones at $1716.63 \mathrm{~cm}^{-1}$ for $\mathrm{M} 2$ and $1717.12 \mathrm{~cm}^{-1}$ for M3; C-O ether at $1270.32 \mathrm{~cm}^{-1}$ for M2 and $1271.36 \mathrm{~cm}^{-1}$ for M3, whereas PEI characteristics peak lost include peak of N-H (1० amine) (M2); $\mathrm{N}=\mathrm{C}=\mathrm{O}$ at $2159.62 \mathrm{~cm}^{-1}$ and $\mathrm{N}-\mathrm{H}\left(2^{\circ}\right.$ amines) (M3). The presence of functional groups $-\mathrm{CF}$ and $-\mathrm{HF}$ typical molecules of PVDF that was less reactive to acids which were dispersed in the membrane matrix has inhibited further decomposition. The decrease in the intensity and loss of characteristics peak was more significant in pure PEI (M6) membranes which have more functional groups that more reactive acids. This condition is evident on the IR spectra of the M1; M2; M3 and M6 membrane before and after treatment in sulfuric acid that presented in Fig.-8.

In line with the results of chemical tests in acid solutions, the membrane chemical test results in alkaline environments with certain concentration and time of immersion show low resistance of PVDF, PVDF/PEI blended and PEI membrane in alkaline environments, especially in strong bases such as sodium hydroxide. Visually, this low chemical resistance is characterized by physical changes of pure PVDF (M1) membrane which gradually turns brown and then black after treatment in $80 \%$ by weight of sodium hydroxide and a similar condition is also shown by pure PEI (M6) membrane which gradually changes to purplish to blackish after treatment in the same environment. The PVDF low chemical stability in the alkaline environment is strengthened by the occurrence of significant changes in peak intensity at 1971.40 $\mathrm{cm}^{-1}$ and $1231.51 \mathrm{~cm}^{-1}$ which each predicted closely related to the change of the $\mathrm{C}=\mathrm{C}$ and $-\mathrm{HF}$ group in the matrix of the composite membrane, as shown in Fig.-9. In addition, treatment in a strongly alkaline environment ( $80 \mathrm{wt} . \% \mathrm{NaOH}$ ) has induced the occurrence of dehydrofluorination events, ie the loss of $\mathrm{HF}$ functional groups from the PVDF molecular structure. The event of dehydrofluorination is closely related to the membrane color change from white to black. These results are in line with the publication of Karkhanechi, et al. which shows response with the samecolor change of the treated membrane in the sodium hydroxide environment for several hours ${ }^{42}$. Dehydrofluorination in PVDF has led to a new peak appearance ( $\mathrm{C}=\mathrm{C}$ functional group) on the M1 membrane spectra, as shown in Fig.-9.

Increased stirring time has an impact on increasing the homogeneity of membrane particles in the cast solution. This condition has increased the complexity of the membrane matrix, making it difficult for further diffusion of alkaline solutions to deeper parts and inhibiting the continuity of decomposition on the M3 membrane. In general, the chemical resistance of PVDF, PVDF/PEI, and PEI membranes to alkaline environments seems comparable. Compared to chemical resistance in alkaline environments, PVDF/PEI and PEI membranes appear to have better chemical resistance in acidic environments. 
RASĀYAN J. Chem.

Vol. 12 | No. 2 |975 - 986| April - June | 2019

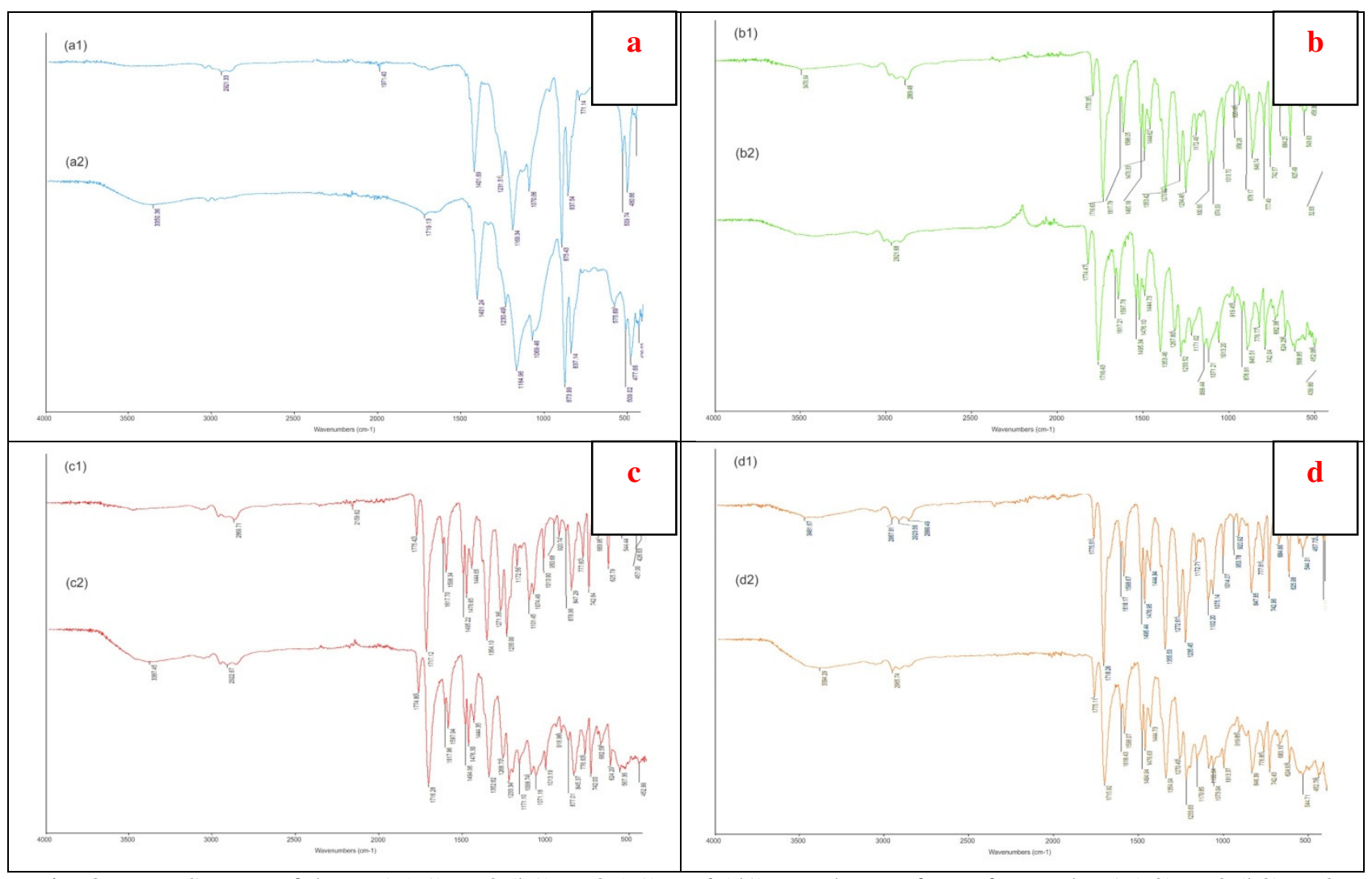

Fig.-8. FTIR Spectra of the: M1 (a1); M2 (b1); M3 (c1); M6 (d1) Membranes for Before and M1 (a2); M2 (b2); M3 (c2); and M6 (d2) Membranes for After Immersion in 80vol.\% Sulfuric Acid

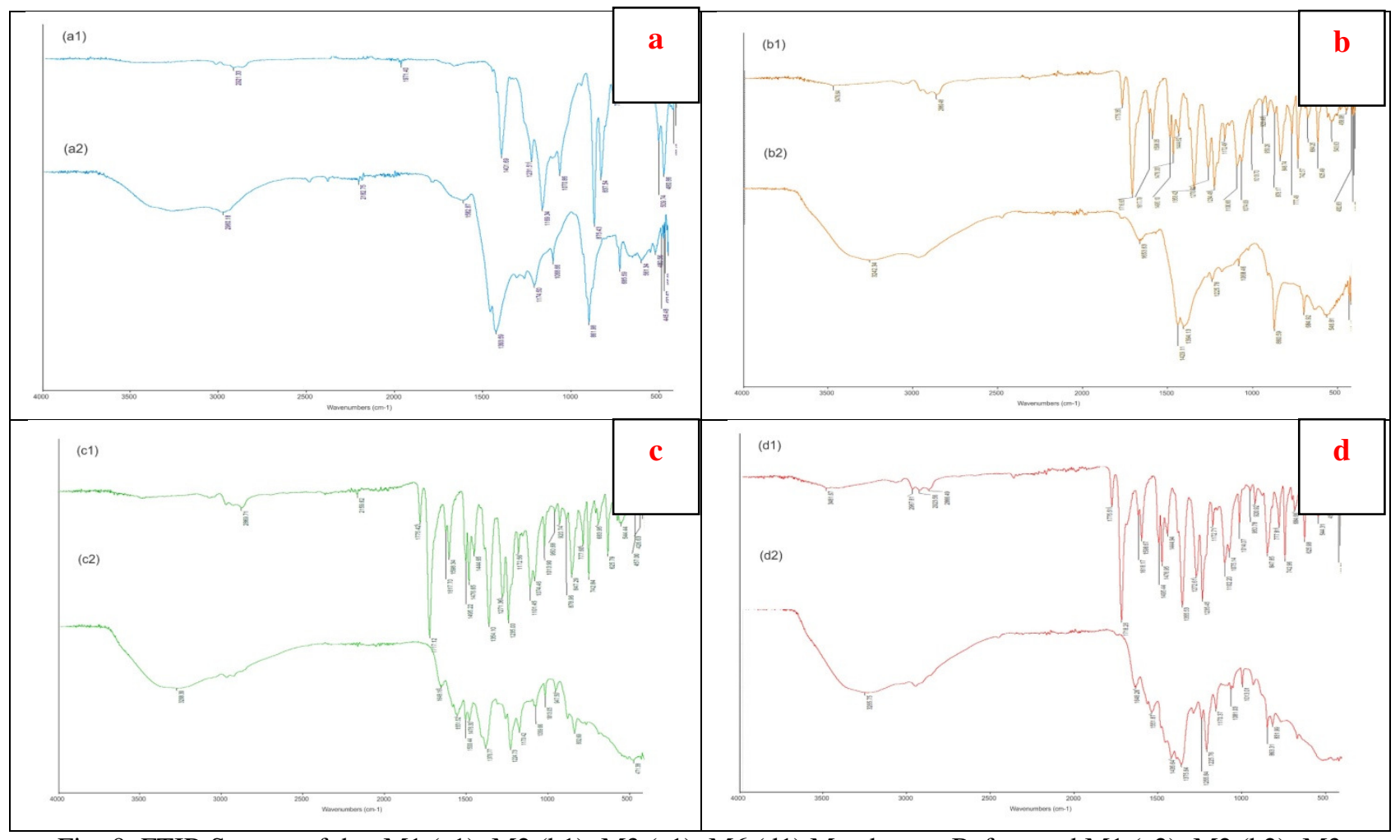

Fig.-9. FTIR Spectra of the: M1 (a1); M2 (b1); M3 (c1); M6 (d1) Membranes Before and M1 (a2); M2 (b2); M3 (c2); M6 (d2) Membranes After Immersion in 80wt.\% Sodium Hydroxide 
RASĀYAN $J$. Chem.

Vol. 12 | No. 2 |975 - 986| April - June | 2019

\section{CONCLUSION}

PVDF/PEI blended membranes with different stirring times have been prepared using NIPS. The effects of different stirring times for cast solutions preparation against chemical, physical and mechanical characteristics, performance, thermal as well as chemical stability have been evaluated. All PVDF/PEI blended membranes are detected as symmetric membranes. Increased cast solution stirring time caused no significant change in porosity, but not so with micropore and macrovoid size which is found to be smaller. The increased stirring time of the cast solution has increased the mechanical resistance of the membrane to external load applications. In addition to causing increased mechanical strength, a significant decrease in membrane pore size along with increased stirring time has induced decreased PWF as well as increased thermal and chemical stability.

\section{ACKNOWLEDGMENT}

The author would like to thank the Indonesian Ministry of Research and Technology of Higher Education for financial support and Chemistry Department of Universitas Negeri Surabaya for research facilities and infrastructure support.

\section{REFERENCES}

1. B. Onal-Ulusoy, Journal of Food Quality, 296(2015), DOI:10.1111/jfq.12140

2. W. T. Xu, Z. P. Zhao, M. Liu, K. C. Chen, Journal of Membrane Science,49(1), 110(2015), DOI: $10.1021 / \mathrm{cr} 800208 \mathrm{y}$

3. J. Gao, J. Yu, C. Li, International Journal of Nonlinear Sciences and Numerical Simulation, 37, 41 (2010), DOI:10.1016/j.memsci.2015.05.024

4. J. Gao, J. Yu, C. Li, International Journal of Nonlinear Sciences and Numerical Simulation, 37 (2010), DOI:10.1515/IJNSNS.2010.11.1.37

5. M.O. Mavukkandy, M. R. Bilad, A. Giwa, S.W. Hasan, H.A. Arafat, Journal of Materials Science, 28, 4341 (2016), DOI: 10.1007/s10853-016-9744-7

6. N. Kusumawati, P. Setiarso, S. Muslim, N. Purwidiani, Rasayan J. Chem., 2(16), 279 (2018), DOI: 10.7324/RJC.2018.1112018

7. K. Ishihara, M. Kobayashi, N. Ishimaru, I. Shinohara, Polym J, 6(25), 631 (1984), DOI: $10.1295 /$ polymj.16.625

8. A. M. Mika, R. F. Childs, J. M. Dickson, Journal of Membrane Science, 45, 56 (1999), DOI: $10.1016 / \mathrm{S} 0376-7388(98) 00246-4$

9. L. Xiao, D. M. Davenport, L. Ormsbee, D. Bhattacharyya, Ind. Eng. Chem. Res, 41(4), 4182 (2015), DOI: $10.1016 / \mathrm{S} 0376-7388(98) 00246-4$

10. N. Kusumawati, P. Setiarso, S. Muslim, Rasayan J. Chem., 10(34), 1041 (2018)

11. F. Liu, N.A. Hashim, Y. Liu, M.R.M. Abed, K. Li, Journal of Membrane Science, 1, 27 (2011), DOI: 10.1016/j.memsci.2011.03.014

12. Y. Li, S. Huang, S. Zhou, A.G. Fane, Y. Zhang, S. Zhao, J. Membr. Sci, 15(4) , 163 (2018), DOI:10.1016/j.memsci.2018.04.004

13. N. Kusumawati, T. Koestari, S. Muslim, Res. J. Pharm. Biol. Chem. Sci,69(2), 72 (2016). DOI: $10.7324 /$ RJC.2018.1112018

14. R. D. C. Ningrum, N. Kusumawati, Int. J. Adv. Sci. Eng. Inform. Tech, 7(16), 720 (2016). DOI: $10.18517 /$ ijaseit.6.5.911

15. D. J. Miller, D.R. Dreyer, C.W. Bielawski, D.R. Paul, B.D. Freeman, AngewandteChemie International Ed. 56, 4(6), 4711 (2017), DOI:10.1002/anie.201601509

16. D. Rana, T. Matsuura, Chemical Reviews, 24(48), 2471 (2010), DOI:10.1021/cr800208y

17. X. Yang, B. Zhang, Z. Liu, B. Deng, M. Yu, L. Li, H. Jiang, J. Li, J. of Materials Chemistry, 11(9), 11915 (2011), DOI:10.1039/C1JM11348H

18. Y. Chang, C.-Y. Ko, Y . J. Shih, D. Quémener, A. Deratani, T. C. Wei, D. M. Wang, J. Y. Lai, J. of Membran Sci, 1(6), 169 (2009), DOI:10.1016/j.memsci.2009.08.039

19. A. Bhattacharya, B.N. Misra, Progress in Polymer Science, 6(7), 814 (2004), DOI: 10.1016/j.progpolymsci.2004.05.002 
RASĀYAN $J$. Chem.

Vol. 12 | No. 2 |975 - 986| April - June | 2019

20. L. F. Fang, B. K. Zhu, L. P. Zhu, H. Matsuyama, S. Zhao, J. of Memb. Science, 2(3), 244 (2017), DOI:10.1016/j.memsci.2016.11.026

21. L. F. Fang, S. Jeon, Y. Kakihana, J. i. Kakehi, B.-K. Zhu, H. Matsuyama, S. Zhao, Journal of Membrane Science, 3(6), 335 (2017), DOI:10.1016/j.memsci.2017.01.044

22. L. F. Fang, H. Matsuyama, B. K. Zhu, S. Zhao, Journal of Applied Polymer Science, 8(3), 45844 (2018), DOI:10.1002/app.45832

23. N. Kusumawati, A. Wijiastuti, A.B.Santoso, Res. J. Pharm. Biol. Chem. Sci, 4(5), 503 (2015)

24. J. H. Jiang, L. P. Zhu, H.-T. Zhang, B.-K. Zhu, Y.-Y. Xu, Journal of Membrane Science, 7(3), 81 (2014), DOI:10.1016/j.memsci.2014.01.043

25. N. Li, J. Zhang, Y. Tian, J. Zhao, J. Zhang, W. Zuo, Chemical Engineering Journal, 16(5), 174 (2016), DOI:10.1016/j.cej.2016.06.088

26. X. Li, R. Pang, J. Li, X. Sun, J. Shen, W. Han, L, Desalination, 4(16), 56 (2013), DOI:10.1016/j.desal.2013.05.021

27. S. Gharabli, J. Kujawa, M. O. Mavukkandy, T. A. Agbaje, E. M. Hamad, H. A. Arafat, European Polymer Journal, 15(3), 164 (2018), DOI:10.1016/j.eurpolymj.2018.01.027

28. W. Albrecht, F. Santoso, K. Lutzow, T. Weigel, R. Schomacker, A. Lendlein, J. Membr. Sci.29(2), 157 (2007), DOI:10.1016/j.memsci.2007.01.027

29. C. S. Ong, P. S. Goh, W. J. Lau, N. Misdan, A. F. Ismail, Desalination3(9), 15 (2016), DOI:10.1016/j.desal.2016.01.007

30. X. Fang, J. Li, X. Li, S. Pan, X. Sun, J. Shen, W. Han, L. Wang, B. Van der Bruggen, J. of Colloid and Interface Science5(5), 652 (2017), DOI:10.1016/j.jcis.2017.06.067

31. W. Albrecht, F. Santoso, K. Lutzow, T. Weigel, R. Schomacker, A. Lendlein, J. Membr. Sci.29(2), 157 (2007), DOI:10.1016/j.memsci.2007.01.027

32. Z. K. Xu, L. Q, Shen, Q. Yang, F. Liu, S. Y. Wang, Y. Y. Xu, J. Membr. Sci, 2(3), 118 (2003), DOI: $10.1016 / \mathrm{S} 0376-7388(03) 00312-0$

33. W. N. W. Salleh, A. F. Ismail, Sep. Purif. Technol, 80(2), 541(2011), DOI:10.1016/j.seppur.2011.06.009

34. S. A. Hashemifard, A. F. Ismail, T. Matsuura, Chem. Eng. J, 17(5), 316 (2011), DOI:10.1016/j.cej.2011.03.063

35. D. Bouyer, W. Werapun, C. Pochat-Bohatier, A. Deratani, J. Membr. Sci, 349, 97 (2010), DOI:10.1016/j.memsci.2009.11.036

36. N. Kusumawati, P. Setiarso, M.M. Sianita, S. Muslim, Indo. J. Chem,18, 257 (2018), DOI: $10.22146 / \mathrm{ijc} .27272$

37. A. F. Ismail, A. Mansourizadeh, J. Membr. Sci, 36(5), $319 \quad$ (2010), DOI:10.1016/j.memsci.2010.09.021

38. N. Peng, N. Widjojo, P. Sukitpaneenit, M.M. Teoh, G.G. Lipscomb, T.S. Chung, J.Y. Lai, Prog. Polym. Sci, 37, 1401 (2002), DOI:10.1016/j.progpolymsci.2012.01.001

39. Y. Liu, G. H. Koops, H. Strathmann, J Membr. Sci, 223(2), 187 (2003), DOI:10.1016/S03767388(03)00322-3

40. K.Y. Lin, D. M. Wang, J. Y. Lai, Macromolecules, 35, 6697 (2002), DOI:10.1021/ma020073y

41. G.H. Bakeri, T. Matsuura, A.F. Ismail, J. Membr. Sci, 383, 159 (2011), DOI:10.1016/j.memsci.2011.08.048

42. E. P. Setyaningsih, M. Machfudzoh, W. P. Utomo, H. Fanzuri, Indo. J. Chem, 16(1), 257 (2016), DOI: $10.22146 /$ ijc. 21172

43. H. Karkhanechi, M. Vaselbehagh, S. Jeon, A. R. Shaikh, Dm. Wang, H. Matsuyama, Polymer, 145, 310 (2018), DOI:10.1016/j.polymer.2018.04.074

[RJC-5104/2018] 